\title{
EDITORIAL
}

\section{Notes from the editorial team}

\section{Henrik Åström Elmersjö (on behalf of the editorial team)}

$\mathrm{T}$ The Nordic Journal of Educational History has moved to a new location in cyberspace (http://journals.ub.umu.se/index.php/njedh), as a consequence of an update to the OJS-platform. All our content, both new and old, has also been equipped with DOI numbers, making it easier to find online. With this issue and the special issue published in Fall 2019 we have reached the milestone of 50 original published articles.

This issue of the journal contains four articles. The first one, by Leif Yttergren, is about the career and lifestyle of female physical education teachers during the twentieth century (1932-1973). The author shows how these women, unlike many women of their time, chose to stay in their careers combining their profession with family life, even though it meant difficulty in bringing their "life puzzles" together.

The second article, by Nikolas Glover, is about the foundation of the relationship between Swedish and Tanzanian adult educators. The article argues for the concept of "aidification" in an effort to explain how transnational educational policy was transformed following decolonisation and the ideal of creating an equal partnership.

Finnish scholars Päivi Marjanen and Mika Metsärinne examine the major changes to Finnish school craft from the middle of the nineteenth century to present day. The analysis shows that the subject has changed substantially in order to stay relevant in different times, but at the same time, the aim has always been to develop useful skills for everyday life.

The last article of this issue, by Andreas Hellerstedt, deals with the problem of innate natural talent versus acquired knowledge or virtue in dissertations on education from Uppsala University, Sweden, near the end of the seventeenth century. The analysis shows that the dissertations described education in Renaissance humanistic terms and that they displayed trust in the capabilities of education. 